\title{
Geotechnical Maps for Angle of Internal Friction of An-Najaf Soil-Iraq Using GIS
}

\author{
Sohaib Kareem Al-Mamoori ${ }^{\mathbf{1}}$ | Sabreen L. Kareem ${ }^{\mathbf{2}}$ | Laheab A. Al-Maliki ${ }^{\mathbf{3}}$ | Khaled El-Tawil ${ }^{4}$
}

\section{Affiliations}

1,2 Department of Environmental Planning, Faculty of Physical Planning, University of Kufa, Najaf, Iraq.

sohaib.almamoori@uokufa.edu.iq sabreenl.kareem@uokufa.edu.iq

3 Department of Hydraulic Engineering Structures, Faculty of Water Resources Engineering, University of Al-Qasim Green, Babylon, Iraq. laheab.almaliki@wrec.uoqasim.edu.iq

4 Faculty of Engineering, Lebanese University,Beirut, Lebanon. khaled tawil@ul.edu.lb,

\section{Correspondence}

Sohaib Kareem Al-Mamoori, Email: sohaib.almamoori@uokufa.edu.iq Received:

29-November-2020

Revised:

11-December-2020

Accepted:

15-December-2020

Doi: 10.31185 /ejuow.Vol8.Iss2.166

\begin{abstract}
The angle of internal friction value $(\varphi)$ is used to describe the soil resistance to shear failure. It is estimated experimentally either from Direct Shear Test or Triaxial Stress Tests. Because of the high cost needed for conducting field tests, it has become essential to find alternative and practical methods to predict soil characteristics for non-spatial data areas. The objective of this study is to specify the best interpolation method to predict the angle of internal friction and use it to produce geotechnical maps for parts of An-Najaf province-Iraq; these parts are the city centre An-Najaf and Kufa city. Furthermore, the study describes the strength and type of soil strata. The results show that the Local Polynomial Interpolation (LPI) is the ultimate and the most significant method to interpolate the angle of internal friction. Moreover, the angle of internal friction $\varphi$ values is ringing between (20-46) degrees, which represent medium to dense soil resistance to shear, while the mean values of $\varphi$ ranged between 34.3 36.18 and represent good resistance to shear failure. This indicates that the Density of Sand is medium to dense, and N60 values range from 10-50. This kind of map would ease the engineers and decisionmakers to decide the suitability of the construction site to carry loads, and the selection the foundation type. The benefits also extend to selecting urban expansion alternatives and for the delimitation of future trends for land-use-development processes in the metropolitan area of An-Najaf city, mainly at local and regional scales.
\end{abstract}

Keywords: Geotechnical mapping, GIS, Angle of Internal Friction, An-Najaf.

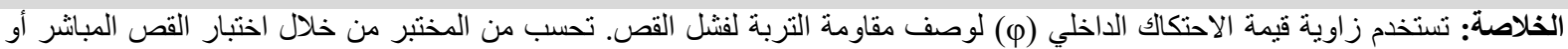

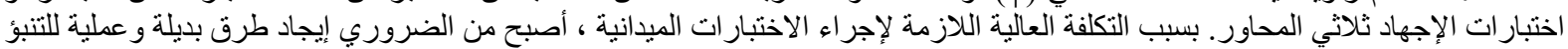

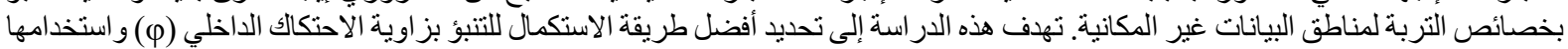

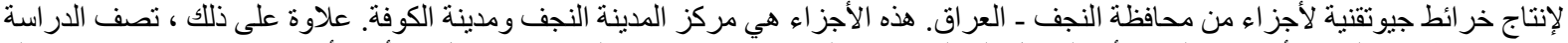

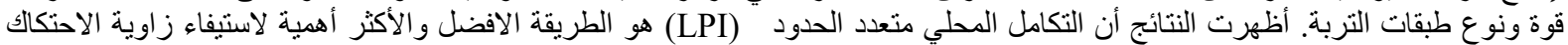

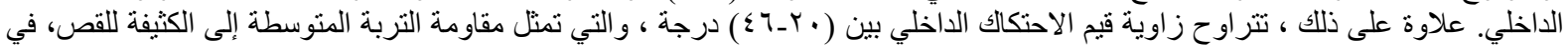

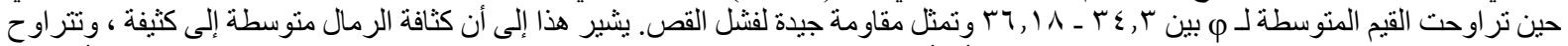

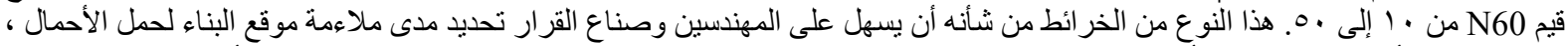

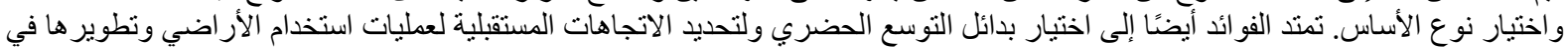

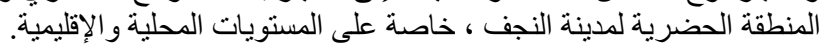

\section{INTRODUCTION}

Understanding the soil-foundation interaction is essential to engineers for appropriate foundation design and selection the better choice, and since the foundations are often located under the surface layers of soil, and their loads' effect extends to the underlying soil strata, this understanding would be through soil investigation tests. These tests require drilling boreholes and collecting samples for laboratory tests in addition to conducting field tests. In general, these tests are expensive and require time and effort. However, engineers are not always able to 
conduct these tests, so they rely on the results of previous tests carried out by their peers for areas close to the project to estimate approximate values for some soil properties [1]. This procedure had been used by many scholars around the world, and with the development of science and technology, it has become easier to interpolate a set of data to find values for non-spatial data areas. One crucial software program used for this task is the Geographical information system (GIS), which represents a powerful tool to store, interpolate, retrieve, visualize, and display data [2]. GIS has been used for creating a geotechnical database of engineering soil properties for many countries and cities. W. Wan-Mohamad and A. Abdul-Ghani (2011) recommended the use of GIS tools to process and present the geotechnical data into more useful forms such as maps [3]. S. Al-mamoori et al. (2020) used GIS to classify soil according to USCS for An-Najaf city [4]. An analyses of Metro Manila soil bearing capacity in Philippine using the GIS have been performed [5]. The list extends to many different soil characteristics such as land suitability [6], seismic risk assessment [7-9], Landslide susceptibility [10], sulfate content [11, 12], the bearing capacity [13-15], and gypsum content [16]. However, there are few studies concerning the angle of internal friction, which is a shear strength parameter that is very significant in assessing the stability of soil and slopes as it reflects the soil shear resistance [17]. Soil angle of internal friction is the measure of the soil resistance to shear forces and represents the angle measured between the normal stresses [18] and the resultant force within the soil that is obtained just as the failure occurs due to a shear stresses $[19,20]$. Roopnarine et al. (2012) point up to the significance of soil friction angle for soil and slope instability, and he classified the soils of Trinidad into friction angle categories for both peak and residual friction angle [18]. Mohammad Mehedi Hasan and Md. Abdur Rashid conducted an experimental study to determine the friction angle of soil through latterly developed double-punch test method [21].

This study aims to assess the best interpolation technique to create the angle of internal friction geotechnical maps for An-Najaf city soil. As well as describe the soil types and assessing its strength based on the angle of internal friction. The eventual maps will provide a preview of the proposed project sites and help designers, engineers, and decision-makers to determine the suitability of the site and the most appropriate type of foundations proposed in the preliminary studies.

\section{MATERIALS AND DATA}

GIS software was used to create the angle of internal friction of soil $(\varphi)$ geotechnical maps. The data were collected first. Then the boreholes coordinates were designated using the GPS device. All data were sorted using the Excel software to match the GIS environment. Figure 1 shows the study methodology:

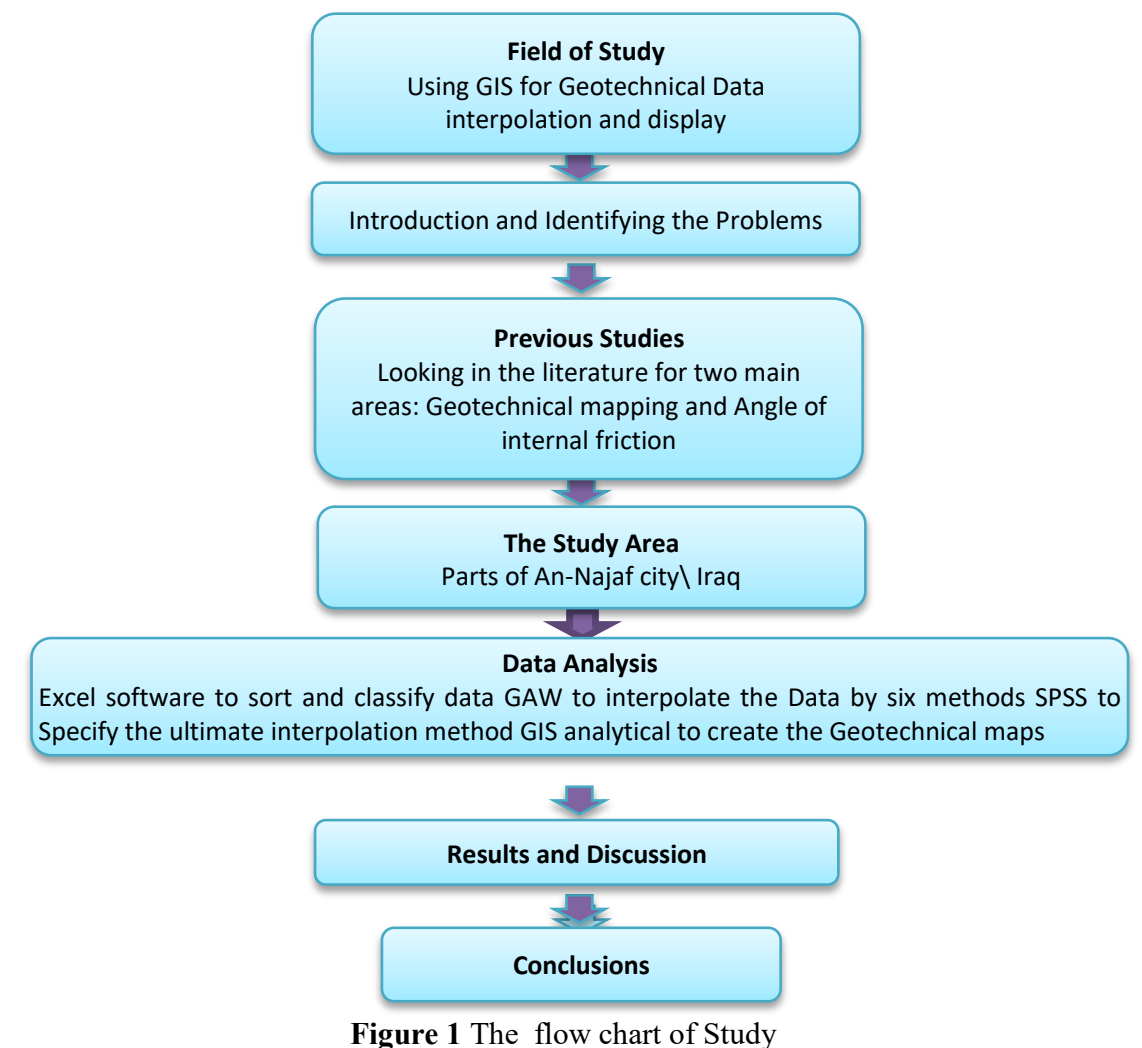

Figure 1 The flow chart of Study 


\subsection{The Location of Study}

An-Najaf city (including Kufa) is bounded by 31.933 latitudes and 44.2833 longitudes. It covers an area of about $105.1 \mathrm{~km}^{2}$ An-Najaf city has 81 neighbourhoods as shown in Fig. 2.

Arid and semi-arid are the main characteristics of An-Najaf climate city. The summer is hot and dry, with an average temperature of $45^{\circ} \mathrm{C}$ [22]. The winter is short, cold [23], and wet, with an average temperature of $24^{\circ} \mathrm{C}$ [24]. The average total annual rainfall is $100 \mathrm{~mm}$ in the wet period and $30 \mathrm{~mm}$ in the dry [11].

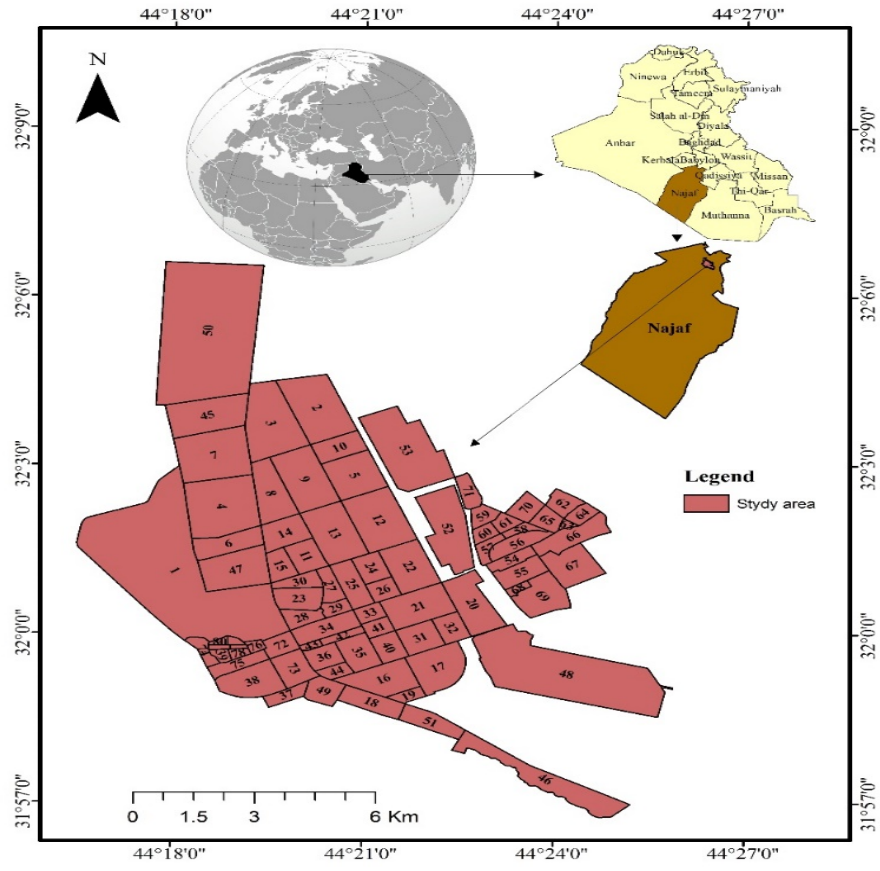

Figure 2 The map of location of study

\subsection{Data}

The study is dependent on data from soil samples, which collected from 464 sites in the study area. The utilized data were taken from the "National Center for Construction Laboratories and Researches (NCCLR)Babylon" based on a cooperation memo. NCCLR- Babylon is a division of the "Iraqi National Center for Construction Laboratories and Research (NCCLR)". The site locations are shown in Figure 3. The sectors' numbers on the map refer to the neighbourhoods listed in table 1.

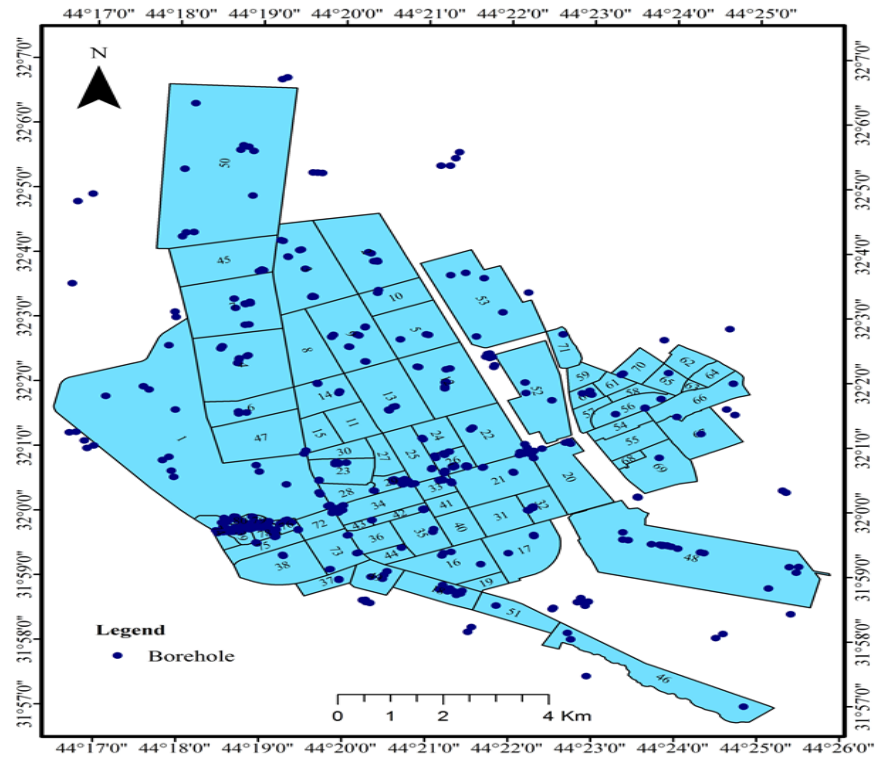

Figure 3 Soil Samples Locations 
Table1. Neighbourhoods Numbers

\begin{tabular}{|c|c|c|c|c|c|c|c|}
\hline Num & Neighborhood & Num & Neighborhood & Num & Neighborhood & Num & Neighborhood \\
\hline 1 & Wadi Al Salam & 22 & Al Adala & 43 & Abu Khalid & 64 & Al Rashadiea \\
\hline 2 & Al Askari & 23 & Al Hussien & 44 & Al Mahdi & 65 & Al Jamhooriea \\
\hline 3 & Al Makrama & 24 & Al Furat & 45 & Al Meelad Al Jadeed & 66 & Al Safeer \\
\hline 4 & Al Nasr & 25 & Al Ghadeer & 46 & Al Radhawiea & 67 & Al Furat \\
\hline 5 & Al Wafa'a & 26 & Civil Offices & 47 & Al Rahma & 68 & $\begin{array}{l}\text { Door Al } \\
\text { Ma'amal }\end{array}$ \\
\hline 6 & Abu Talib & 27 & Al Karama & 48 & Najaf National Airport & 69 & $\begin{array}{l}\text { Al Sadr Al } \\
\text { Thalith }\end{array}$ \\
\hline 7 & Al Meelad & 28 & Al Sahha & 49 & Scientific City & 70 & Al Suhayliea \\
\hline 8 & Al Jam'iea & 29 & $\begin{array}{c}\text { Al Ulama'a \& Al } \\
\text { Shuara'a }\end{array}$ & 50 & Al Nida'a & 71 & Al Sahla \\
\hline 9 & Al Urooba & 30 & Al Zahra'a & 51 & $\begin{array}{c}\text { Najaf Technical } \\
\text { Institute }\end{array}$ & 72 & Al Jidayda 1 \\
\hline 10 & Al Indiea & 31 & Al Qadissiea & 52 & Kufa University & 73 & Al Jidayda 3 \\
\hline 11 & Al Ghari & 32 & Al Askan & 53 & Meesan & 74 & Tourism Zone \\
\hline 12 & Al Jami'aa & 33 & Al Sa'ad & 54 & Kinda2 & 75 & Al Jidayda 2 \\
\hline 13 & Al Salam & 34 & & 55 & Maytham Al Tammar & 76 & $\begin{array}{c}\text { Commercial } \\
\text { Zone }\end{array}$ \\
\hline 14 & Al Salam Al jadeed & 35 & Adan & 56 & Kinda 1 & 77 & Imam Ali Shrine \\
\hline 15 & Al Atibba'a & 36 & Al Mua'alimeen & 57 & Al Shurta & 78 & Al Buraq \\
\hline 16 & Al Ansar & 37 & Al Shurta & 58 & Al Mua'alimeen & 79 & Al Mishraq \\
\hline 17 & Al Harafieen & 38 & Al Jidayda 4 & 59 & Al Askari & 80 & Al Emara \\
\hline 18 & Al Quds2 & 39 & Al Hwoayash & 60 & Al Mutanabbi & 81 & $\begin{array}{l}\text { Al Sooq Al } \\
\text { Kabeer }\end{array}$ \\
\hline 19 & Al Quds1 & 40 & Al Hawra’a & 61 & Al Jamia'a & & \\
\hline 20 & Al Sina'ei & 41 & Al Eshtiraki & 62 & Al Jedaydat & & \\
\hline 21 & Al Ameer & 42 & Al Muthanna & 63 & Al Waqf & & \\
\hline
\end{tabular}

\subsection{The angle of Internal Friction $\varphi$}

The angle of Internal Friction $(\boldsymbol{\varphi})$ is obtained mathematically by the graph (Mohr's Circle) of the shear stress and normal effective stresses at which the shear failure happened as illustrated in Figure 4. The combination of the friction angles with slope is based on the relationship established in the Mohr Columb failure criterion, which indicates that soil friction angle is a component of shear strength such that:

$$
\tau_{f}=\sigma \tan \varphi+c
$$

Where:

$\tau_{f}$ : The shear strength

$\boldsymbol{\sigma}$ : The applied normal stress

$(\boldsymbol{\varphi})$ : internal angle of friction soil

c: Cohesion of Soil.

Eq. 1 clarifies that the shear strength increases if the angle of internal friction increased, and the failure accurse if the shear stress overcomes the shear strength.

The angle of internal friction $(\varphi)$ of cohesionless soil is frequently estimated from field test results because of difficulty in obtaining undisturbed cohesionless soil samples for laboratory soil tests. It can be determined in the laboratory by the Direct Shear Test or the Triaxial Stress Test (TST) [1]. Typical values of ( $\boldsymbol{\varphi}$ ) for cohesionless soil range from 30-40 degrees. Friction angle increases with increasing particle angularity and with decreasing void ratio [2]. For this study, the angle of internal friction data was obtained by the Direct Shear Test. $(\boldsymbol{\varphi})$ values can give an indication of the soil type and the soil relative density $\mathrm{Dr}$ as shown in table 2 . 


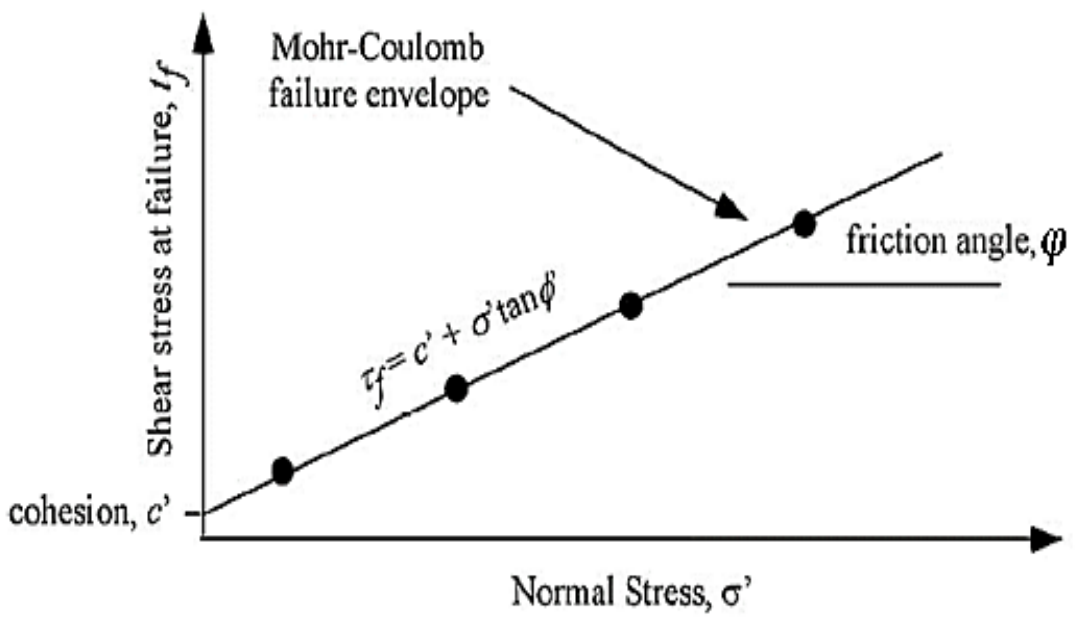

Figure 4 Mohr-Coulomb failure envelope [25]

Table 2. The angle of Internal Friction of Sands $\boldsymbol{\varphi}$, and soil type [3].

\begin{tabular}{|l|c|c|c|c|c|}
\hline \multicolumn{1}{|c|}{ Soil Type } & $\begin{array}{c}\text { Relative Density } \\
\text { Dr, percent }\end{array}$ & $\begin{array}{c}\text { Standard } \\
\text { Penteration } \\
\text { Resistance N60 } \\
\text { (Terzaghi and } \\
\text { Peck 1967) [25] }\end{array}$ & Meyrhof (1974) & $\begin{array}{c}\text { Friction Angle } \\
\boldsymbol{\varphi} \text {, deg. Peck, } \\
\text { Hanson and } \\
\text { Thornbum } \\
\text { (1974) [26] }\end{array}$ & Meyrhof (1974) \\
\hline Very Loose & $<20$ & $<4$ & $<30$ & $<29$ & $<30$ \\
\hline Losse & $20-40$ & $4-10$ & $30-35$ & $29-30$ & $30-35$ \\
\hline Medium & $40-60$ & $10-30$ & $35-38$ & $30-36$ & $35-40$ \\
\hline Dense & $60-80$ & $30-50$ & $38-41$ & $36-41$ & $40-45$ \\
\hline Very Dense & $>80$ & $>50$ & $41-44$ & $>41$ & $>45$ \\
\hline
\end{tabular}

The soil particle shape (rounded or angular) affects and would change the above angles by about four degrees [3].

\section{METHOD}

The maps of the angle of internal friction were performed by ArcGIS 10.7 using Geostatistical Analyst Wizard GAW GAW has two types of interpolation techniques, which are deterministic and geostatistical, and each type has a group of interpolation methods [27]. Most of the methods depending on the resemblance of points to produce a surface or grid [28-30].

In this paper, both interpolation techniques were used. The deterministic interpolation techniques, including four methods (IDW, Local Polynomial Interpolation (LPI), Radial Basis Functions (RBF) and Global Polynomial Interpolation (GPI)), and the geostatistical interpolation techniques, has two methods (OK and Empirical Bayes Kriging (EBK) were used for mapping the soil angle of internal friction.

\section{RESULTS AND DISCUSSION}

To create the angle of internal friction, geotechnical maps first, the best interpolation method that gives the most accurate results must be specified. Therefore; the data were imported to the GAW and interpolated by the six available methods, namely Inverse Distance Weighting IDW, Local Polynomial Interpolation (LPI), Radial Basis Functions (RBF), Global Polynomial Interpolation (GPI), Ordinary Kriging (OK), and Empirical Bayes Kriging (EBK). The interpolation results were then imported into the SPSS software to specify the optimum interpolation method by applying the Backward Elimination Regression. BER, as mentioned, is the best and simple statistical way to examine and specify the optimal interpolation method because it removes the least variable in the model each time and repeats the model again and again for the remaining variables until it reduces them to one most significant variable. BER has been applied to six interpolation methods (Table 3). The results of the BER test show that There are three optimal and most significant interpolation methods, namely IDW, RBF, 
and LPI. However, since the LPI method has lest Standardized error (0.158) comparing to the IDW and RBF, then it was used to produce the geotechnical maps.

Table 3. BER Results to specify the Ultimate Interpolation Method

\begin{tabular}{|c|c|c|c|c|c|c|c|}
\hline \multicolumn{8}{|c|}{ Coefficients } \\
\hline \multirow{2}{*}{\multicolumn{2}{|c|}{ Model }} & \multicolumn{2}{|c|}{$\begin{array}{c}\text { Unstandardized } \\
\text { Coefficients }\end{array}$} & \multirow{3}{*}{$\begin{array}{c}\begin{array}{c}\text { Standardized } \\
\text { Coefficients }\end{array} \\
\text { Beta } \\
\end{array}$} & \multirow[t]{2}{*}{$\mathbf{t}$} & \multirow[t]{2}{*}{ Sig. } & \multirow{2}{*}{$\begin{array}{c}\text { Correlations } \\
\text { Zero-order }\end{array}$} \\
\hline & & B & Std. Error & & & & \\
\hline \multirow{7}{*}{1} & [4] & 4.892 & 4.239 & & 1.154 & .250 & \\
\hline & GPL & -.048 & .192 & -.010 & -.252 & .801 & .201 \\
\hline & IDW & .972 & .215 & .761 & 4.516 & .000 & .939 \\
\hline & RBF & 1.090 & .496 & .716 & 2.197 & .029 & .912 \\
\hline & EPK & .034 & .203 & .009 & .169 & .866 & .396 \\
\hline & $\mathrm{OK}$ & -.183 & .364 & -.108 & -.502 & .617 & .888 \\
\hline & LPI & -1.002 & .182 & -.482 & -5.496 & .000 & .753 \\
\hline \multirow{6}{*}{2} & {$[4]$} & 4.834 & 4.212 & & 1.148 & .253 & \\
\hline & GPL & -.025 & .132 & -.005 & -.189 & .850 & .201 \\
\hline & IDW & .976 & .214 & .763 & 4.564 & .000 & .939 \\
\hline & RBF & 1.059 & .460 & .695 & 2.303 & .023 & .912 \\
\hline & $\mathrm{OK}$ & -.157 & .330 & -.093 & -.476 & .635 & .888 \\
\hline & LPI & -.988 & .161 & -.475 & -6.147 & .000 & .753 \\
\hline \multirow{5}{*}{3} & [4] & 4.141 & 2.074 & & 1.997 & .047 & \\
\hline & IDW & .980 & .212 & .767 & 4.625 & .000 & .939 \\
\hline & RBF & 1.068 & .457 & .701 & 2.339 & .021 & .912 \\
\hline & $\mathrm{OK}$ & -.173 & .317 & -.103 & -.547 & .585 & .888 \\
\hline & LPI & -.989 & .160 & -.476 & -6.185 & .000 & .753 \\
\hline \multirow{4}{*}{4} & [4] & 3.796 & 1.971 & & 1.926 & .056 & \\
\hline & IDW & 1.008 & .205 & .789 & 4.916 & .000 & .939 \\
\hline & RBF & .888 & .316 & .583 & 2.810 & .006 & .912 \\
\hline & LPI & -1.001 & .158 & -.481 & -6.327 & .000 & .753 \\
\hline
\end{tabular}

ArcGIS 10.7 was used to produce the geotechnical maps for four depths up to 20 meters. The data were interpolated over the study area using the LPI interpolation method to characterize the spatial distribution of the soil internal friction angle. The statistical analyses are also performed, and the details were discussed for each depth.

\subsection{Building the Model}

Figure 5 presents the spatial distribution of the angle of internal friction for the study area and for four ranges of depths (i.e., 5, 10, 15, and 20 meters).

The study area was divided into four layers with a five meters depth for each layer then as shown in table 4. the statistical analysis of the results indicates the following:

- (Layer-1) has values ranging from $20^{\circ}-44^{\circ}$ and Mean $(\mu)=35.63$.

- In (Layer-2) the values of $\boldsymbol{\varphi}$ range between $22^{\circ}-50^{\circ}$ and mean $(\mu)=36.18$, which is the highest value among the layers, and this indicates the high roughness and shear resistance.

- (Layer-3), has the lowest values for $\boldsymbol{\varphi}$, that ranged between $23^{\circ}-43^{\circ}$ and mean $(\mu)=34.63$, which indicates low shear resistance.

- In (Layer-4), $\boldsymbol{\varphi}$ values ranged between $23^{\circ}-43^{\circ}$ and mean $(\mu)=35.91$, where the values of the layers are medium. 

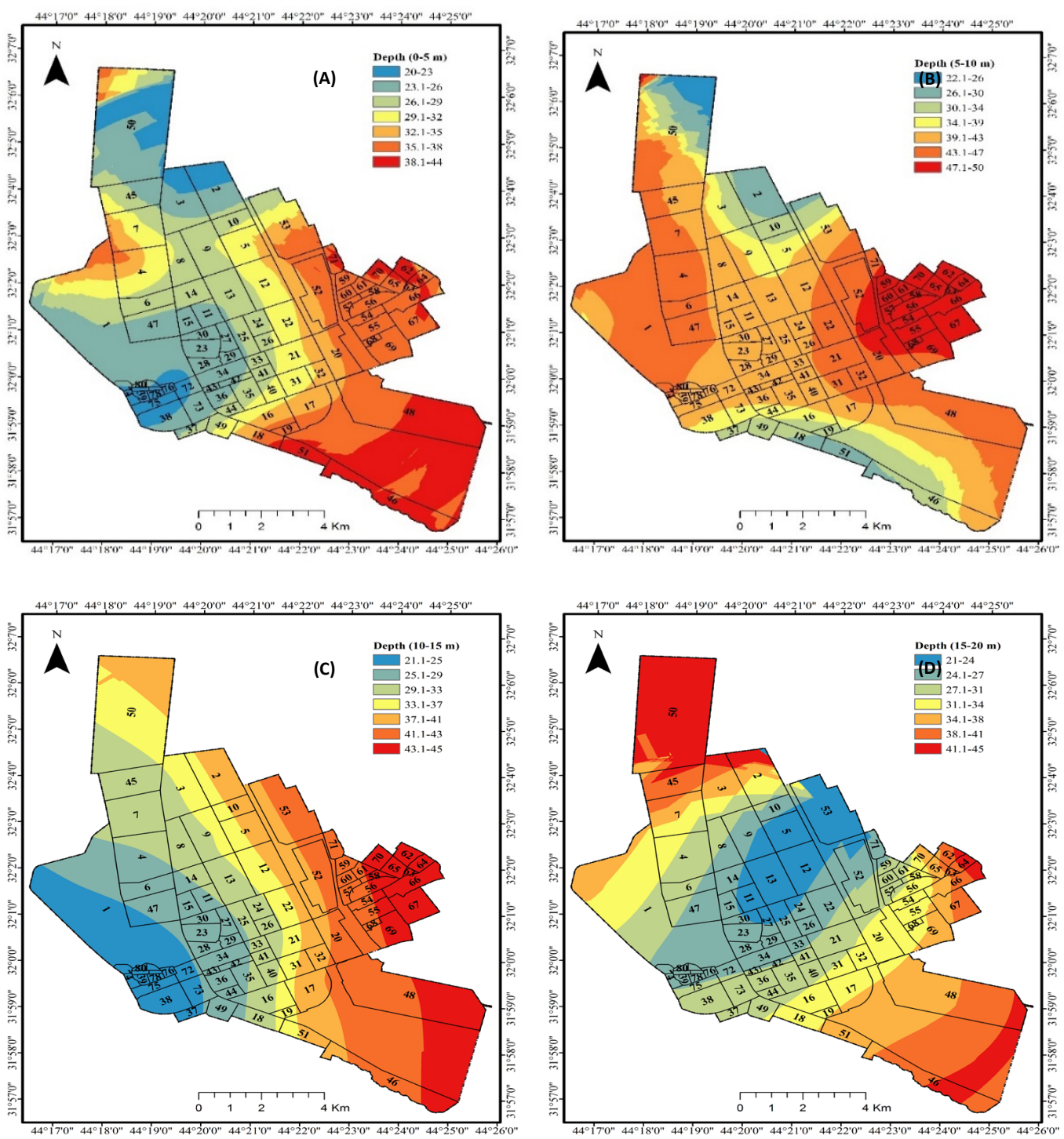

Figure 5 The Spatial Distribution of the Angle of Internal Friction for Depths: (A) 0-5 m, (B) 5-10 m, (C) 10-15m, and (D).

Table 4. Results of the statistical analysis of $(\varphi)$ values with depth

\begin{tabular}{|c|c|c|c|c|c|c|c|}
\hline Layers & $\begin{array}{c}\text { Distribution } \varphi^{\circ} \\
\text { with depth }\end{array}$ & $\begin{array}{c}\text { No. of } \\
\text { Data }\end{array}$ & $\begin{array}{c}\text { Mean } \\
(\mu)\end{array}$ & $\begin{array}{c}\text { StDev } \\
(\sigma)\end{array}$ & COV $(\%)$ & Range $(\varphi)^{\circ}$ & Figure \\
\hline Layer-1 & $\boldsymbol{\varphi}^{\circ}(0-5) \mathrm{m}$ & 196 & 35.63 & 4.288 & 0.12 & $20^{\circ}-44^{\circ}$ & Fig6-A \& Fig7-A \\
\hline Layer-2 & $\boldsymbol{\varphi}^{\circ}(5-10) \mathrm{m}$ & 228 & 36.18 & 4.181 & 0.11 & $22^{\circ}-50^{\circ}$ & Fig6-B \& Fig7-B \\
\hline Layer-3 & $\boldsymbol{\varphi}^{\circ}(10-15) \mathrm{m}$ & 196 & 34.63 & 4.559 & 0.13 & $23^{\circ}-43^{\circ}$ & Fig6-C \& Fig7-C \\
\hline Layer-4 & $\boldsymbol{\varphi}^{\circ}(15-20) \mathrm{m}$ & 152 & 35.91 & 5.53 & 0.154 & $21^{\circ}-46^{\circ}$ & Fig6-D \& Fig7-D \\
\hline
\end{tabular}

On the other hand, the values of the angle of internal friction in the soil of An-Najaf city are considered high and give a clear indication of its cohesion and resistance to shear failure, as mean values ( $\mu$ ) range from 34.63-36.18. Moreover, depending on Table 2, this indicates that the Density of Sand is medium to dense and the values of $\mathrm{N}_{60}$ are ranging from 10-50. To determine the exact values of $\boldsymbol{\varphi}$ for any point at any depth, maps in Figure 5, will be used. The results in table 4 were also plotted in Figures 6 \& 7. 

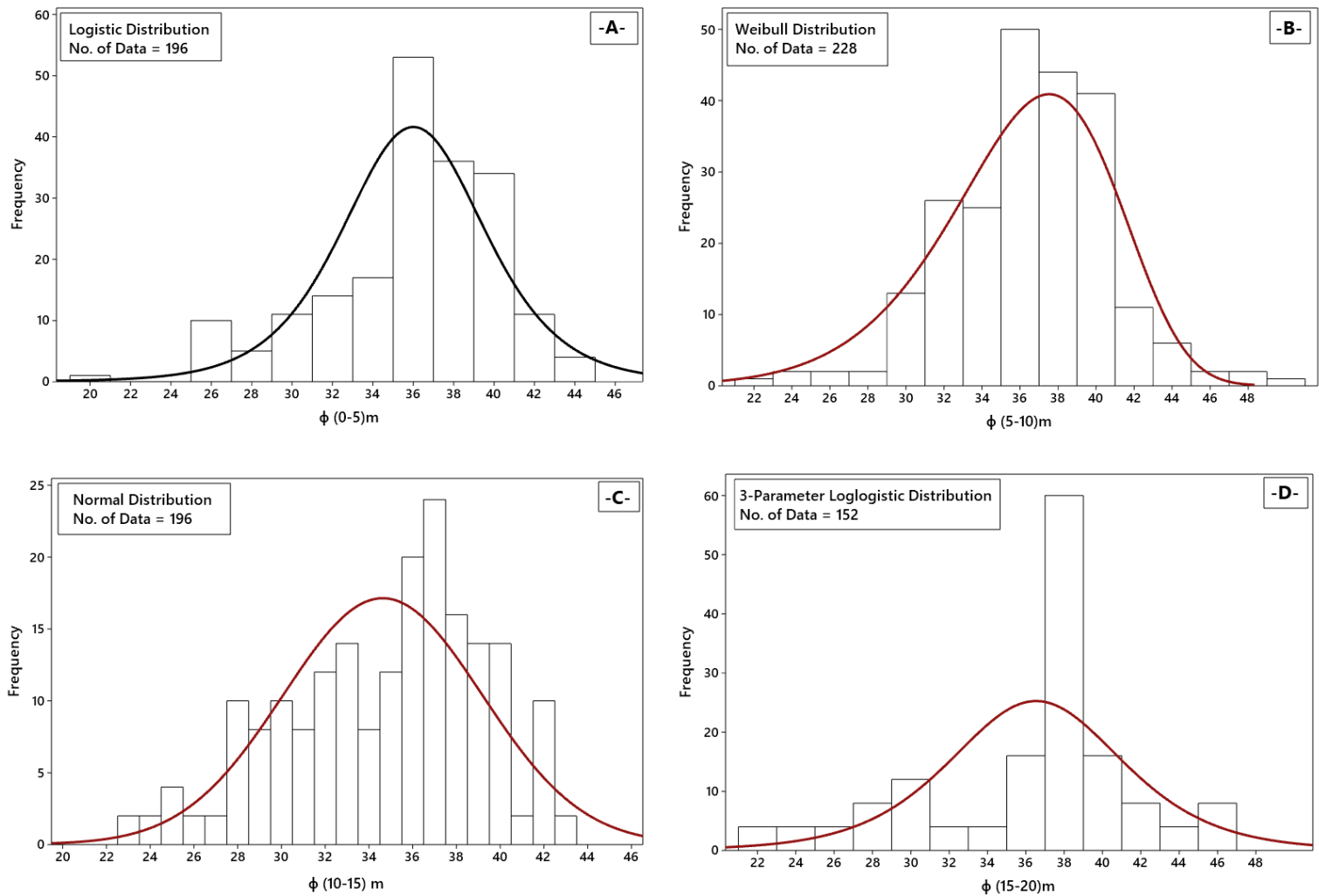

Figure 6 Histogram and Distribution function for the angle of internal friction for depths: (A) (0-5) m (B) (5-10) m, (C) (1015) $\mathrm{m}$, (D) (15-20) $\mathrm{m}$.

The mean value of each depth is presented in Figure 7, along with the standard deviation
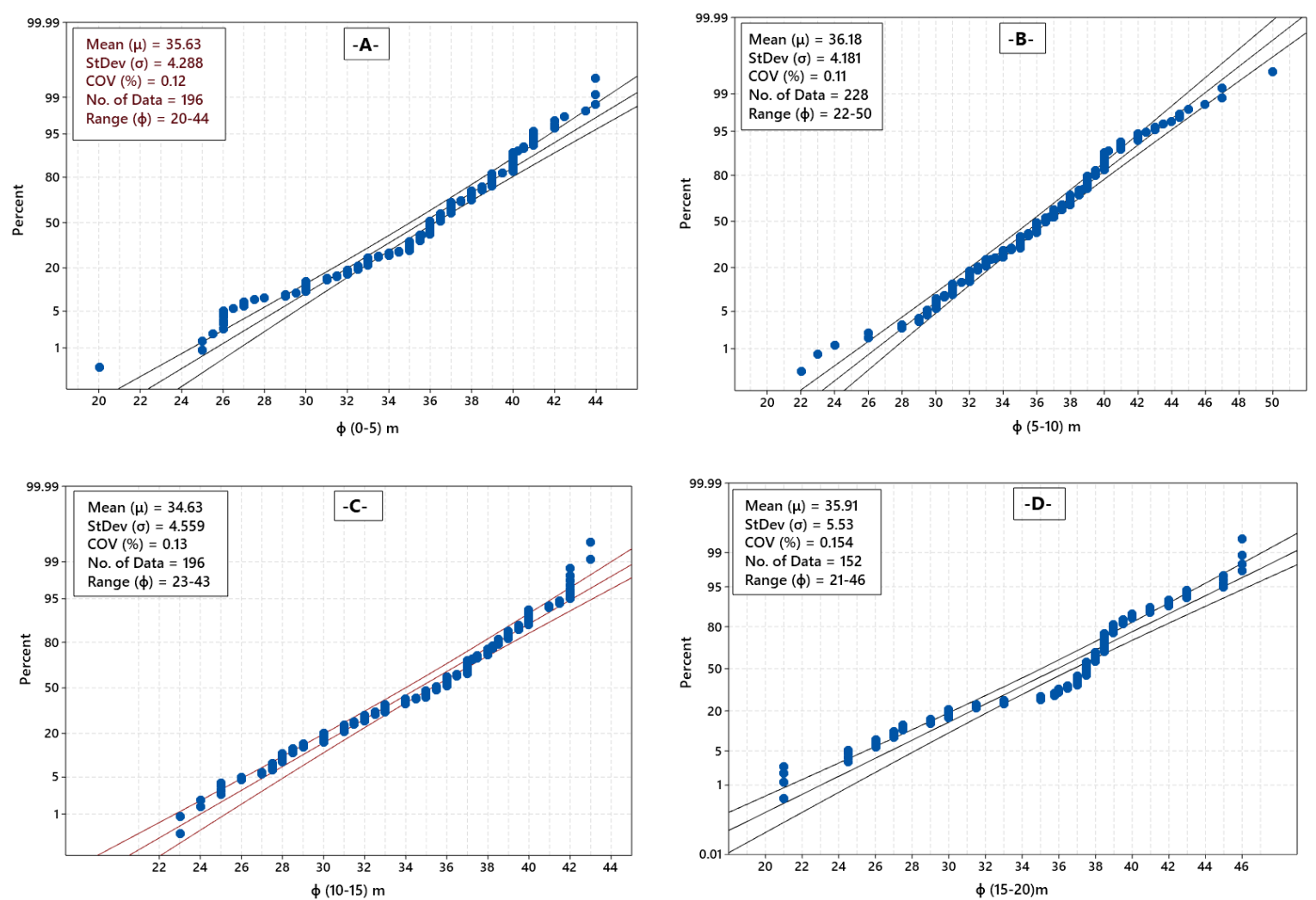

Figure 7 Probability function of the An-Najaf City soil for the angle of internal friction for depths: (A) (0-5) m (B) (5-10) m, (C) $(10-15) \mathrm{m}$, (D) $(15-20) \mathrm{m}$. 


\section{CONCLUSIONS}

With economic development and population growth in An-Najaf city, the need for a large number of new buildings is arises, most of which are constructed in new areas where there is a lack of information about the soil layers properties. Therefore, the presence of an economical solution to predict soil behaviour is essential. In this research, the angle of internal friction has been interpolated by six different methods to determine the ultimate one using the Backward elimination regression. The results indicate that the EBK, IDW, and LPI were the most significant methods. Moreover, the spatial distribution was presented by the GIS software using the LPI interpolation method because it has the least standard error. However, the angle of internal friction values for depths 0-10m range (35-41) degree, while for 10-15 m were (28-43) degree, and for 15-20m were (37-39) degree. These values give an indication for the soil type and can be used for estimating other soil properties as well as estimating soil bearing capacity.

This kind of map proposes a vigorous database for the study area; also, they ease understanding the data visually. As well, using these maps will help saving expenses along with time and effort. As well, using these maps will help saving expenses along with time and effort. Another advantage for producing geotechnical maps for soil bearing capacity is to be used as a guide for engineers and decision-makers to decide the best choice for any construction design, the most suitable foundation design, and the appropriate treatment needed. Finally, the results of this paper might be used for Laying the foundations of smart cities.

\section{REFERENCES}

1. Valverde-Palacios, I., et al., (2014). Geotechnical map of Holocene alluvial soil deposits in the metropolitan area of Granada (Spain): a GIS approach. Bulletin of Engineering Geology and the Environment, 73(1):(177192), https://doi.org/10.1007/s10064-013-0540-1

2. Ahmed, C., A. Mohammed, and A. Tahir, (2020). Geostatistics of strength, modeling and GIS mapping of soil properties for residential purpose for Sulaimani City soils, Kurdistan Region, Iraq. Modeling Earth Systems and Environment, 6:(879-893), https://doi.org/10.1007/s40808-020-00715-y

3. Wan-Mohamad, W.N.S. and A.N. Abdul-Ghani, (2011). The Use of Geographic Information System (GIS) for Geotechnical Data Processing and Presentation. Procedia Engineering, (20):397-406. https://doi.org/10.1016/j.proeng.2011.11.182

4. Al-Mamoori, S.K., et al., (2020). Horizontal and Vertical Geotechnical Variations of Soils According to USCS Classification for the City of An-Najaf, Iraq Using GIS. Geotechnical and Geological Engineering, (38):19191938, https://doi.org/10.1007/s10706-019-01139-x

5. Dungca, J.R., et al., (2017). Soil Bearing Capacity Reference for Metro Manila, Philippines. International Journal of GEOMATE, (12):5-11, http://dx.doi.org/10.21660/2017.32.6556

6. Ostovari, Y., et al., (2019). GIS and multi-criteria decision-making analysis assessment of land suitability for rapeseed farming in calcareous soils of semi-arid regions. Ecological Indicators, (103): 479-487. https://doi.org/10.1016/j.ecolind.2019.04.051

7. Sun, C.-G. and H.-S. Kim, (2017). GIS-based regional assessment of seismic site effects considering the spatial uncertainty of site-specific geotechnical characteristics in coastal and inland urban areas. Geomatics, Natural Hazards and Risk, (8):1592-1621, https://doi.org/10.1080/19475705.2017.1364305

8. Nwe, Z.Z. and K.T. Tun, (2016). Seismic Hazard Analysis using AHP-GIS. Int. J. Res. Chem. Metallurg. Civ. Eng, (3):1442-1450.

9. Al-Mamoori, S.K., et al., (2020). Seismic Risk Assessment of Reinforced Concrete Frames at An-Najaf CityIraq Using Geotechnical Parameters. Lecture Notes in Civil Engineering, Chapter 28.

10. Nohani, E., et al., (2019). Landslide susceptibility mapping using different GIS-based bivariate models. Water, 11(7):1402. https://doi.org/10.3390/w11071402.

11. Al-Mamoori, S.K., et al., (2018). Distribution of Sulfate Content and Organic Matter in An-Najaf And AlKufa Cities'soil Using GIS. Kufa Journal of Engineering, 9(3):92-111. https://www.iasj.net/iasj?func=article\&aId $=148027$ 
12. Mohammed, A.H., AY Yahya, and BA. Ahmed, (2012). Database for Baghdad Soil Using GIS Techniques. Journal of Engineering, 18(12):1307-1324. https://www.iasj.net/iasj?func=article\&aId=62697

13. Sahib Mohammed, M., M. Falih Hasan, and K. Satea Al-bayati, (2020). Geotechnical maps for Salah AlDeen-Iraq. MS\&E, 737(1): 012224. 10.1088/1757-899X/737/1/012224

14. Al-Maliki, LAJ, et al., (2018). Bearing capacity map for An-Najaf and Kufa Cities using GIS Engineering,. 10(05): 262. https://doi.org/10.4236/eng.2018.105018

15. Aldefae, A.H., J. Mohammed, and H.D. Saleem, (2020). Digital maps of mechanical geotechnical parameters using GIS, Cogent Engineering, 7(1):1779563. https://doi.org/10.1080/23311916.2020.1779563

16. Al-Mamoori, S.K., (2017). Gypsum Content Horizontal and Vertical Distribution of An-Najaf and Al-Kufa Cities' Soil by Using GIS, Basra Journal of Engineering Sciences, 17(1):48-60. https://www.iasj.net/iasj?func $=$ article $\&$ aId $=156113$

17. Bareither, C.A., et al., (2008). Geological and physical factors affecting the friction angle of compacted sands. Journal of geotechnical and geoenvironmental engineering, 134(10): 1476-1489. https://doi.org/10.1061/(ASCE)1090-0241(2008)134:10(1476)

18. Roopnarine, R., G. Eudoixe, and D. Gay, (2012). Soil physical properties as predictors of soil strength indices: Trinidad case study. Geomaterials, 2(01): 1. http://dx.doi.org/10.4236/gm.2012.21001

19. Coulomb, C.A., (1973). Essai sur une application des regles de maximis et minimis a quelques problemes de statique relatifs a l'architecture (essay on maximums and minimums of rules to some static problems relating to architecture). https://trid.trb.org/view/124803

20. Skempton, A., (1964). Long-term stability of clay slopes. Geotechnique, (14):77-102.

21. Hasan, M.M. and M.A. Rashid, (2017). Determination of friction angle of soil using double-punch test approach: An experimental study. Cogent Engineering, 4(1): 1419415. https://doi.org/10.1080/23311916.2017.1419415

22. Kareem, SLK, et al., (2020). Optimum Location For Landfills Landfill Site Selection Using GIS Technique: Al-Naja City As A Case Study, Cogent Engineering, 1(1): 1520119. https://doi.org/10.1080/23311916.2020.1863171

23. Farhan, SL, IA Jasim, and SK. Al-Mamoori, (2019). The transformation of the city of Najaf, Iraq: Analysis, reality and future prospects. Journal of Urban Regeneration \& Renewal, 13: 160-171. https://www.ingentaconnect.com/content/hsp/jurr/2019/00000013/00000002/art00006

24. Al-Mamoori, S.K., et al., Chloride, (2019). Calcium Carbonate and Total Soluble Salts Contents Distribution for An-Najaf and Al-Kufa Cities' Soil by Using GIS Geotechnical and Geological Engineering, 37(3): 22072225. https://doi.org/10.1007/s10706-018-0754-x

25. Kalinski, M.E., (2011). Soil Mechanics Lab Manual, 2nd Edition.: John Wiley \& Sons, Incorporated. https://www.cabdirect.org/cabdirect/abstract/20123318331

26. Powrie, W., (2018).Soil mechanics: concepts and applications.: CRC Press. https://books.google.co.uk/books?hl=en\&lr=\&id=F1 fOBQAAQBAJ\&oi=fnd\&pg=PP1\&dq=Soil+mechanics

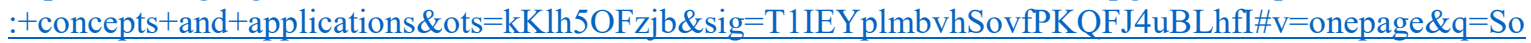
il $\% 20$ mechanics $\% 3 \mathrm{~A} \% 20$ concepts $\% 20$ and $\% 20$ applications $\& \mathrm{f}=$ false

27. Al-Maliki, LAJ, et al., (2020). Simple Statistical Way to Determine the Best GIS Interpolation Method, Bearing Capacity Soil samples at An-Najaf City-Iraq a Case Study. AJGS, 10(28).

28. Li, J. and A.D. Heap, (2008). A review of spatial interpolation methods for environmental scientists.

29. Johnston, K., et al., (2001).Using ArcGIS geostatistical analyst. 380: Esri Redlands.

30. Chang, K.-T., (2006). Introduction to geographic information systems. McGraw-Hill Higher Education Boston. https://eric.ed.gov/?id=EJ443381

31. Jasim, IA, SL Farhan, and SK. AL-MAMOORI, (2017). Smart Government: Analysis of Shift Methods in Municipal Services Delivery: The Study Area: Al-Kut-Iraq. Journal of kerbala university, 15(3):1-15. https://www.iasj.net/iasj?func $=$ article\&aId $=132033$. 